\title{
From SARS to pandemic influenza: the framing of high-risk populations
}

\author{
Tracey L. O'Sullivan ${ }^{1}$ (D) $\cdot$ Karen P. Phillips ${ }^{1}$
}

Received: 6 June 2018 / Accepted: 12 February 2019 / Published online: 22 February 2019

(c) Springer Nature B.V. 2019

\begin{abstract}
The 2003 global outbreak of severe acute respiratory syndrome (SARS) was a wake-up call for health systems in Canada, with realization of occupational health risks faced by health care workers and first responders in public health emergency response. The need for investment in critical social infrastructure-including explicitly articulated plansbecame a priority for managing future pandemics. Over the past 15 years, pandemic planning has evolved with the adoption of a whole-of-society approach to disaster risk reduction. There is recognition of the social gradient of risk, which emerges from the interaction between social determinants of health, risk of exposure, and adverse impacts from a pandemic. Additionally, there is better understanding of the benefits of planning according to functional needs, rather than deficit-oriented labelling. In this paper, we reflect on how the framing of vulnerable or high-risk populations has evolved since SARS. Looking to the future, we present the imperative for the creation of institutional space for engagement of high-risk populations in pandemic planning processes, including participatory governance. Innovative consultation strategies are needed to enhance collective asset literacy and ensure planning is adaptive to the changing social fabric. Progressive pandemic planning in the next decade must be inclusive and sensitive to modern definitions of family, varied abilities, cultural practices and gender and sexual diversity, thereby reflecting a whole-ofsociety approach to disaster risk reduction.
\end{abstract}

Keywords Pandemic planning · Vulnerable populations · Whole-of-society · Disaster resilience $\cdot$ Gender $\cdot$ Disability

\section{Introduction}

Pandemic planning has undergone a shift in the past two decades with the understanding of multi-level factors that promote community resilience. In particular, there has been increased recognition of the functional needs and assets of high-risk populations. Community organizations (such as The Canadian Red Cross, food banks, shelters) are

Tracey L. O’Sullivan

tosulliv@uottawa.ca

1 Interdisciplinary School of Health Sciences, Faculty of Health Sciences, University of Ottawa, 25 University Pvt., Ottawa, ON K1N 6N5, Canada 
acknowledged as essential partners across different levels of government, for their expertise in providing supportive services to high-risk populations (Choudhury and Haque 2018; Lemyre et al. 2009). In this paper, we reflect upon this shift that has occurred since the global outbreak of severe acute respiratory syndrome (SARS) and highlight considerations for future investment in disaster risk reduction using an inclusive, whole-of-society approach.

The 2003 global outbreak of SARS was a wake-up call—underscoring lack of preparedness in health care settings and the occupational health risks faced by health care workers during large-scale outbreaks. In Canada, there were 438 probable cases of SARS, and 3 of the 44 deaths were health care workers in Toronto who had been exposed at work (National Advisory Committee on SARS and Public Health 2003). While certain segments of the population were known to be at increased risk for serious illness during infectious respiratory outbreaks (e.g. people who are immune-compromised and pregnant women), at that time the vulnerability of health care workers in their workplaces was not widely acknowledged (O’Sullivan and Amaratunga 2009).

Pandemic planning was still in its infancy before the SARS outbreak, and discussions about vulnerable populations were limited to heightened biological risks of morbidity or mortality. In 2004, the creation of the Public Health Agency of Canada (PHAC) was an important investment and commitment to public health at the federal level. Following SARS, avian influenza virus (H5N1) provoked tremendous concern in 2006 given its high human mortality rate and disproportionate impacts for health care workers (PHAC 2015). By 2006, pandemic planning was in full swing and a revised Canadian Pandemic Influenza Plan for the Health Care Sector (CPIP) was published. CPIP was created as a guidance document to inform and support the health care sector in the management of pandemics (PHAC 2015). It outlines the roles, responsibilities and strategies to be used by the federal government to mitigate, prepare for, and respond to large-scale outbreaks of influenza. In 2009, a psychosocial annex was developed to supplement the plan (PHAC 2009). Acknowledgement of occupational risks to health care workers and risks to socially vulnerable groups in society was an important advancement in pandemic planning at that time. Resilience of the broader community is dependent on health care workers and responders being able (and willing) to work during an outbreak; without them health and social systems would collapse and put other people at further risk of adverse outcomes (O'Sullivan et al. 2007).

The emergence of the global H1N1 pandemic (pH1N1) in 2009 put the plans to the test. Indigenous communities were among the earliest communities affected by the pandemic. The Standing Senate Committee on Social Affairs, Science and Technology (2010) summarized the impacts of the outbreak, noting that many social and environmental vulnerabilities contributed to the susceptibility of these communities. Overcrowding, poor housing conditions, lack of access to clean water, underlying poor health and low socio-economic status were among the issues identified. A consultation conducted in partnership between PHAC and the International Center for Infectious Diseases (ICID) explored the H1N1 pandemic experience in terms of at-risk or marginalized populations, making an important distinction between medically at-risk and functionally at-risk (ICID 2010).

In 2010, O'Sullivan and Bourgoin conducted a review of social vulnerability during pandemics, detailing how risk during outbreaks aligns with clustering of social determinants of health to create a social gradient of risk (O'Sullivan and Bourgoin 2010). Populations at social risk were identified according to the social determinants of health listed in Box 1. Gender was noted as a cross-cutting theme-rarely mentioned-but inextricably linked to the social gradient of risk (O'Sullivan and Bourgoin 2010). Recommendations included the need for pandemic preparedness planning to utilize a broader lens-one that 
Box 1 Social categories of risk

Income and income distribution

Social and physical environment

Education and literacy

Employment and working conditions

Early life income and child development

Ethnicity, culture, and language

Age and disability

Gender

Access to health services

O’Sullivan and Bourgoin (2010)

recognizes the intersectionality of the social determinants of health and their collective contributions to pandemic risk. These findings align with those of Kickbusch and Sakellarides (2006) who described a Flu-Smart City as one which focuses on improving the baseline health of communities during the pre-pandemic phase as a strategy to promote resilience when an outbreak occurs.

Fast-forward to 2015 with the most recent edition of CPIP, where revisions align with recommendations from the World Health Organization (WHO) (2009) and United Nations International Office for Disaster Risk Reduction (UNISDR) (2015) for a whole-of-society approach. An important step forward in recognition of persons at heightened social risk during pandemic is the list (Box 2) provided by the federal government (PHAC 2015, p. 14), as a sample of personal, geographic, and social attributes that could render individuals vulnerable during pandemic. This is an important progression in emergency management in terms of recognizing the upstream social determinants of health and their interactions, which in turn exacerbate risk during pandemic.

\section{Functional limitations and deficit-oriented labelling}

In 2007, Enarson and Walsh prepared a seminal report for the Canadian Red Cross outlining the importance of considering high-risk populations in disaster and emergency management. They recommended a change from deficit-oriented labelling to recognition of capabilities that people bring to an event. Deficit-oriented labelling refers to terms that are used to describe people which focus on functional limitations. In contrast, person-first terms focus first on the person and their capabilities and situate the functional limitations as separate from the person.

Box 2 Persons considered to be at heightened social risk during pandemic. Adapted from CPIP (PHAC 2015)

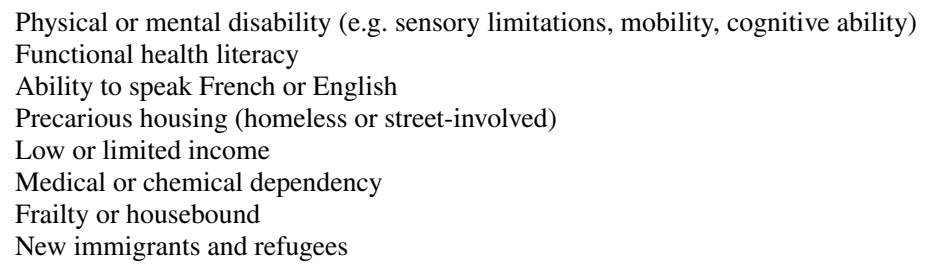


Enarson and Walsh (2007) recommended use of the term high-risk populations rather than vulnerable populations. While their report did not focus specifically on outbreaks, it had obvious applications to the field of disaster and emergency management which had moved to an increased emphasis on all-hazard planning for disasters, including outbreaks at the time of its publication. They identified 10 groups that could be considered high risk for negative impacts during disasters; these included older adults, people with limited income, children and youth, people with low literacy levels, Aboriginal peoples, persons with disabilities, women, people with medical dependencies, transient populations, new immigrants, and people who are members of cultural minorities.

While Enarson and Walsh were bringing attention in Canada to the need to identify high-risk populations and plan specifically to address functional needs, Kailes and Enders (2007), researchers from the USA, published a Function-based Framework for Emergency Management using the acronym C-MIST to represent categories of functional needs that could guide planning for disasters (communication, medical needs, maintaining functional independence, supervision, and transportation). Uptake of this framework in Canada was widespread in the field of emergency management. Recognition of functional needs as a specific planning consideration had started. Over the next few years, the C-MIST framework (Kailes and Enders 2007) was adapted in Canada to incorporate different categories and functions to assist in emergency planning. In 2009, the Centre for Emergency Preparedness and Response and the British Columbia Coalition for Persons with Disabilities expanded on C-MIST by separating the medical category and including an additional category labelled psychosocial (Martin 2009).

In 2009, our team received funding federal funding from the Canadian CBRNE Research Technology Initiative (CRTI) to develop strategies to enhance resilience among high-risk populations to maximize disaster preparedness, response, and recovery. We called ourselves Enhancing Resilience and Capacity for Health (EnRiCH) which quickly developed into interconnected networks of international collaborators, Canadian scientists, and a youth initiative. From 2010 to 2013, The EnRiCH Project highlighted the importance of inclusive engagement of high-risk populations in disaster preparedness, response, and recovery activities. In January 2010, we held a consultation with 20 members of the EnRiCH Advisory Panel to revise the C-MIST framework for use in an asset mapping exercise with five communities in Canada. Through feedback from the communities and pilot testing, the adapted framework was referred to as a Functional Capabilities Framework, to reflect an asset-based approach. We used the acronym CHAMPSS for the following categories: communication, housing, awareness, mobility and transportation, psychosocial, self-care and daily tasks, safety, and security and applied the framework by coding assets in different communities in Canada, (O'Sullivan et al. 2013). Following the revision of the CHAMPSS framework, we conducted an action research project in five communities in Canada where community members-including representatives of high-risk populations-used this framework to map the assets in their communities. This project highlighted strategies for inclusive engagement and collaboration across different organizations and sectors in the community, to support resilience for high-risk populations in different disaster contexts.

One outcome of The EnRiCH Project was the creation of The EnRiCH Community Resilience Framework for High-Risk Populations (O'Sullivan et al. 2014), which has adaptive capacity as the focal point, driven by engagement, collaboration, and innovation (see Fig. 1). This framework highlights four strategic areas that can guide activities to promote resilience: (1) awareness/communication, (2) engagement and networks, (3) asset/resource management, and (4) upstream leadership. In this paper, we outlined the importance of 


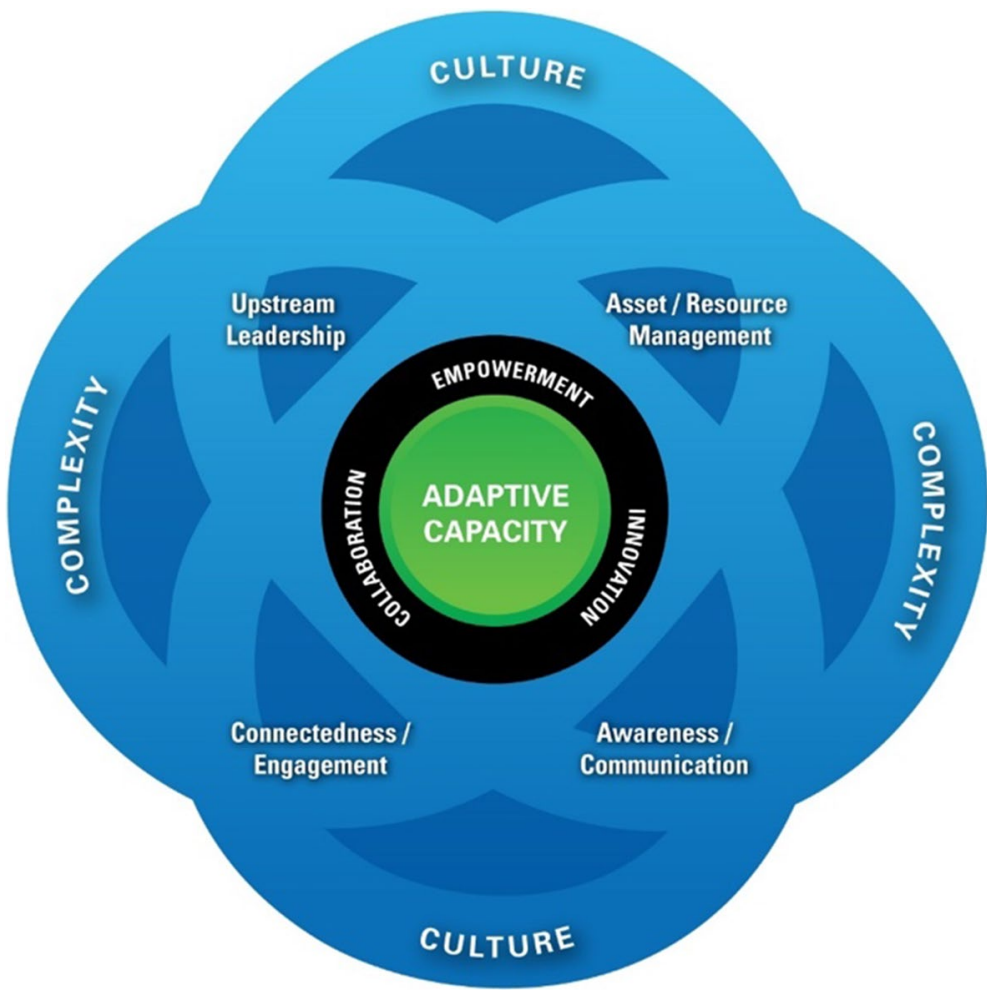

Fig. 1 The EnRiCH Community Resilience Framework for High-Risk Populations. Reprinted with permission from O'Sullivan et al. (2014)

an asset-based approach for a whole-of-society approach to disaster risk reduction, which includes inclusive language to promote social participation among high-risk populations.

\section{Framing of high-risk populations}

Building on the suggestion from Enarson and Walsh (2007) that the term vulnerable populations be replaced with high-risk, over the past decade our team has deliberately challenged how perceptions of vulnerability and capability are reflected in language (O'Sullivan et al. 2014). When people are labelled vulnerable, it is a deficit-oriented frame through which they are being viewed; it conveys negative connotations such as weakness or infirmity. This is particularly apparent when the deficit label comes before the person and becomes the attribute used to describe someone (e.g. disabled person, stroke victim). Alternatively, person-first language puts the person ahead of the functional limitation (e.g. person who is experiencing homelessness vs. homeless person). This discourse respects the dignity of the person and acknowledges there are many different characteristics that make up a person. This point is the essence of asset literacy and underscores the importance of seeing people and their unique asset profiles-not viewing people simply in terms of the functional limitations they require supports for. 
While risk profiles are extremely important in disaster and emergency management and need to be accounted for in response planning, there is a social risk when people are viewed solely through a deficit-oriented lens (O'Sullivan et al. 2014).

A whole-of-society approach must include appropriate language which is respectful and maintains the dignity of high-risk populations. Inclusive language and empowering discourse can influence engagement opportunities for people who represent populations with different functional needs (O'Sullivan et al. 2014). For example, when citizens are invited to a consultation meeting or to participate in asset mapping for their community, the invitation to the consultation is only the first step. It is essential that they not only be able to access the session, but be able to participate in the meeting. This may involve changing the structure or setting of the meeting to facilitate communication, redress power differentials, and create a welcoming space for contribution (O'Sullivan et al. 2014).

Our team is currently completing a discourse analysis of emergency planning documents to explore how populations at heightened risk during disasters are framed. One important example from this study is the leadership demonstrated in the Sendai Framework (UNISDR 2015) with use of the term people at disproportionate risk instead of vulnerable populations. People at disproportionate risk, while cumbersome to pronounce, is an example of person-first language which separates the person from the condition(s) that exacerbate the vulnerability (Pickering et al. 2017).

While understanding risk is essential, recognition of assets among citizens, social networks, and community organizations is fundamental for empowering citizens and asset-based community development (McKnight and Kretzmann 2011). Asset mapping, which was introduced by McKnight and Kretzmann in the 1990s, was designed as an interactive participatory process to identify assets in a community. The recognition of different types of assets and how they might contribute to problem solving is an empowering part of the process. Innovative problem solving is often an outcome of asset mapping as citizens realize how the assets can contribute to their community. Moving from awareness to action in participative disaster risk reduction activities requires opportunity — and evolving viewpoints — to ensure citizen voices are heard and their ideas are given consideration (Pearce 2003).

We have previously defined asset literacy as: 'an understanding of what assets are and their potential contribution, knowing how to mobilize or access different types of assets, and having self-efficacy and motivation to move from awareness to action' (O'Sullivan et al. 2017, p. 1). In our exploratory study with women who were living with the impacts of stroke, we presented these four components of asset literacy as a continuous cycle. Asset literacy is a concept closely related to framing and the use of an asset-oriented approach to disaster risk reduction. People feel empowered when they are asked for input and recognized for their assets and contributions-it is an essential component of co-learning in resilient communities (Chaudhury and Haque 2018). As a first step, people can be supported in identifying their own assets and those within their community. Through consultations and mapping activities, discussion about the value and potential contribution of different assets can facilitate understanding and opportunity for mobilizing individual and collective assets. As people gain understanding of their community and fellow citizens, they become more aware of different opportunities for social participation, which can enhance confidence and motivation to engage. If a whole-of-society approach is to be successful, we believe individual and collective asset literacy must be the foundation (O'Sullivan et al. 2017). 


\section{Evolving societies-where to from here?}

Looking back 15 years, since the outbreak of SARS, the framing of high-risk populations in public health and disaster risk reduction has evolved and there is greater societal recognition of the need for inclusivity. Canada is home to a diverse population which can be expected to be differentially impacted by infectious disease outbreaks, both in terms of biological susceptibility to the pathogen as well as social, geographic, and other vulnerabilities to emerging threats. Canada's population demographics are continuously impacted by geopolitical immigration trends, international refugee crises, and other world events connected with migration. Across the social gradient of disaster risk, we must consider gender as a transversal element, informing and intersecting with social vulnerabilities. Our previous work explored the topics of role conflict in the face of an infectious disease outbreak in Canada. Canadian nurses' anticipated work-family conflicts in terms of child, elder, and pet care, communication needs, and resources and gender-sensitive support for family members of frontline responders were recommended for future policy development (O'Sullivan et al. 2009).

Sex-specific supports recognize the biological susceptibility of women to infectious disease, particularly during pregnancy (Phillips et al. 2011). Certain infectious diseases pose a threat to the developing foetus, but many infectious respiratory diseases including SARS, $\mathrm{H} 1 \mathrm{~N} 1$, and $\mathrm{H} 5 \mathrm{~N} 1$ are associated with significant complications, organ failure, and death for women in late stages of pregnancy (Phillips et al. 2011). Many antiretroviral medications available for infectious respiratory disease treatment have not been approved for use during pregnancy with effects ranging from unknown to teratogenic effects in animal studies (Tanaka et al. 2009). Personal protective equipment (PPE) should be customized to the sexually dimorphic shapes of men and women, not simply scaled by size.

Gender-specific supports may include informational and emotional supports that address work-family conflict, potential risks to partners and children in addition to recognizing that men and women experience and manifest grief, anxiety, and stress in different ways (O'Sullivan et al. 2009). Instrumental supports such as organizational management, occupational supports and interventions, and training may also be gendered (Amaratunga et al. 2010). In most societies, including Canada, the hierarchical organization of institutions is largely male dominated, such that the intersection of gender and power will be magnified during disaster response (Enarson and Morrow 1998; Amaratunga et al. 2010; O'Sullivan and Amaratunga 2009). Male first responders and first receivers may be afforded automatic authority when working in female-dominated professions (Amaratunga et al. 2010). Although women comprise the majority of health-related roles, they are less likely to occupy roles in senior leadership and administration, with gender discrimination, workfamily conflicts and associated constraints and a masculine organizational culture cited as some of the contributing factors (LaPierre and Zimmerman 2012). The underrepresentation of women in leadership roles in health care not only impacts the gendered experience of first responders and first receivers, but also may limit the incorporation of field experience into planning and practice.

In spite of Canadian research into both the sex-based risks and gendered experience of frontline health care workers in the 2003 SARS outbreak (O'Sullivan et al. 2008; O'Connor et al. 2009; Amaratunga et al. 2010; Phillips et al. 2011), a gender lens is not explicitly described in the current CPIP (PHAC 2015); instead, the document focusses on the risks to pregnant women. The Sendai Framework (2015) goes further, recognizing gender, disability, and cultural perspective as essential components for all policies and 
practices and promoting roles for women and youth in disaster leadership. The promotion of gender-equitable disaster response, recovery, rehabilitation, and reconstruction results from the empowerment of women and persons with disabilities (UNISDR 2015). Thus, gender remains a fundamental consideration in infectious disease planning and response.

Preparedness and response actions typically coordinated by government sectors must also engage the trust of Canadians, including Indigenous peoples. The proportion of Indigenous peoples in the Canadian population is increasing, accounting for $4.9 \%$ of the population in 2016 from 2.8\% in 1996 (Statistics Canada 2018). An important social wakeup since the 2003 SARS pandemic is the emergence of the Truth and Reconciliation process in Canada, recognizing the historical cultural genocide of Indigenous peoples caused in part by abuses in government-supported residential schools (Smylie and Firestone 2016). Indigenous peoples in Canada have faced myriad of social, environmental, and biological disasters including the ongoing suicide crisis (Webster 2016), access to safe drinking water (Bradford et al. 2016) and infectious diseases including group A streptococcal (iGAS) infections, rheumatic fever (Bocking et al. 2016), tuberculosis (Patel et al. 2017), and the 2009 pH1N1 (Jung et al. 2017). The sustained high incidence of infectious disease in Indigenous peoples coupled with decreasing incidence in the rest of the Canadian population is suggested to be caused by 'structural violence' such that social structures, institutions, culture, and other factors combine to inform these extreme health disparities (Galtung 1969). Therefore, it is evident that any widespread disaster, including a pandemic, would disproportionately impact Indigenous communities in Canada.

Health disparities in Indigenous peoples have been attributed to colonization, racism, and self-determination (Smylie and Firestone 2016). Many of the recommendations of the Truth and Reconciliation-Call to Action (2015) are related to health including education and cultural competency training of health care professionals, rights to health care, sustainable funding to support capacity for Indigenous specific health centres and health professionals (Truth and Reconciliation Council of Canada 2015). Looking forward, Indigenous peoples are an integral component of any infectious respiratory disease plan, response and recovery process. Indigenous peoples must be invited to contribute to relevant programs, policies, and interventions related to emergency preparedness. CPIP (PHAC 2015) describes Aboriginal peoples as stakeholders consulted in the development of the plans. The Sendai Framework (UNISDR 2015) is more explicit, describing roles for Indigenous peoples within a people-centred approach and to use traditional, Indigenous, and local knowledge and practices to complement scientific knowledge, where appropriate. In Canada, the Federal Ministers met in May 2018 to discuss updates needed for the Federal, Provincial/Territorial (FPT) Emergency Management Strategy for Canada-planned release December 2018. Of note is the inclusion of National Indigenous Organizations in planning. This consultative process is a first step to ensure the updated strategy is inclusive and addresses the identified needs in Indigenous communities. Ongoing consultation, engagement, and integration of traditional knowledge in culturally sensitive ways will be essential (Canadian Intergovernmental Conference Secretariat 2018).

In the past 15 years, Canada and many nations around the world have experienced significant social change in terms of sexual and gender diversity. Lesbian, gay, bisexual, transsexual, queer, and two-spirit (LGBTQ2) Canadians must be recognized as a heterogeneous group with respect to sexual and gender diversity, race/ethnicity, age, geography, and socio-economic status. Some LGBTQ2 Canadians face disproportionate mental health challenges, violence, harassment, discrimination and are overrepresented in low-income brackets (Canadian Mental Health Association-Ontario 2018), which renders this community at high-risk during pandemic. LGBTQ2 Canadians perceive 
themselves to have great strengths including a more developed creativity and heightened social and environmental awareness which are manifested by personal activities and support of social causes (CROP 2017). These values and principles, including divergent thinking, represent significant capacity for emergency planning and preparedness.

Gender, race/ethnicity, disabilities, and sexual identities can be described within a human rights framework. Gostin et al. (2018) posit the conceptualization of health disparities as human rights violations, thereby holding global health organizations accountable to existing rights frameworks. Although LGBTQ2 individuals experience health disparities, particularly related to infectious diseases, globally LGBTQ2 individuals are deprived of rights, face discrimination and even persecution by many governments. In Canada, Prime Minister Justin Trudeau announced several initiatives to improve visibility, equity, dignity, and inclusion for LGBTQ2 Canadians. These include the Positive Space initiative, the identification of a Diversity Champion, and the inclusion of gender-based analysis for all Canadian Armed Forces defence activities (Trudeau 2017). Such initiatives reflect the diversity of Canadians and ensure that our armed forces are not only prepared to carry out disaster response and recovery that is effective, but also equitable, just, and inclusive.

Just as we have experienced societal shifts in sexual and gender diversity, so too has the concept of the traditional nuclear family. As with many countries, the concept of family has evolved in Canada to include singles, multigenerational families, roommates, and samesex couples. Trends in the changing demographics of Canadian families include increases in same-sex unions ( $0.9 \%$ couples) and multigenerational families (Statistics Canada $2017 \mathrm{a}, \mathrm{b})$. The traditional, nuclear family is more than a social construct, but functions as a social structure governed by gender roles to reproduce, nurture, and develop family-specific behaviours and actions (Kirschenbaum 2006). Disasters and emergencies are framed locally as impacts to families including fragmentation, loss, displacement, separation, and survival. Evolution of the demographic composition of the 'traditional' family unit has important implications for gender roles, eligibility of information, emotional supports, and compensation for unmarried individuals in the event of an emergency. Children and youth may face unexpected responsibilities when parents are engaged as frontline responders. In 2016, 19.2\% of Canadian children lived in single-parent households (Statistics Canada 2017c), representing additional challenges if their caregiver is a first responder or is unable to care for children due to illness. An empirical study designed to assess the inherent resilience of the family unit to emergencies reported that single-parent households were more prepared in terms of supplies, skills, and protection compared to dual-headed households (Kirschenbaum 2006). A family unit tends to have more substantial social networks, which in turn contribute to emergency resilience. It is the social networks, not the family structure, that predict disaster preparedness, such that households without children but with significant social networks may be as resilient (Kirschenbaum 2006).

An important advancement in the latest rendition of CPIP (PHAC 2015) is the mention of caregiving as a likely source of workplace absenteeism during pandemic. Anticipated absenteeism due to illness is projected at $25-45 \%$, with caregiving absences representing an additional impact on workplaces. What is missing from this latest plan, however, is the impact on caregivers who are not in traditional workplaces - an often forgotten population at heightened risk. Caregiving provided by family and friends in the home is an important and often invisible contribution to the health system in Canada and other countries. During pandemic, many care recipients may need to seek formal care services if their caregivers are unable to continue providing care due to illness, death, or excessive strain (O'Sullivan 2009). 
In our study of Canadian family caregivers of stroke survivors, we asked participants about their back-up plan for caregiving during a community disaster, such as pandemic (O'Sullivan et al. 2012). The caregivers in this study $(n=19)$ found this question to be overwhelming and in almost all of the cases they had not thought about a back-up plan and found it daunting to think about. After 6 months of providing care support at home for the stroke survivor, none of the families had developed a back-up caregiving plan, and only 3-4 had considered what they might do in the event they needed an alternative. Many cited community care access centres and hospitals as a potential off-the-cuff solution. This study highlights an important consideration for pandemic planning. The assumption of many families that formal respite services will be available during pandemic could present an unanticipated demand on the health system. The framing of high-risk populations needs to include families of people with chronic conditions or disabilities, who are providing invisible supports for the health care system. Informal caregivers are an essential group to engage in the process of pandemic panning to ensure the system can anticipate the demands and family contingency caregiving plans become common practice. Additionally, communication efforts need to focus on building awareness of health care capacity and the implications for service delivery during pandemic.

Youth and the millennial generations represent potential for great social change in Canada. Millennials are a heterogenous cohort, but are differentiated by greater educational attainment, are more ethnically diverse, have a more flexible definition of family, embrace multiculturalism and technology (Environics 2017). Traditionally, the acknowledgement of youth in a disaster context has focused on heightened risk due to maturational development and social dependency on family. In recent years, there has been more awareness about the potential benefits of youth engagement in disaster risk reduction in Canada but expansive action has been more limited (Cox et al. 2017). In 2018, a new initiative began with the creation of a national network around youth engagement in disaster risk reduction. This initiative is being conducted by researchers in Ottawa, Chicoutimi, Victoria, and the Eastern Townships of Quebec_-including a youth group in Lac-Mégantic_in partnership with The Canadian Red Cross. It is our plan to implement an asset-based, whole-of-society approach to create opportunities for youth to innovate and contribute to their communities, while reducing risk and building resilience. An important step forward was the inclusion of youth panellists at the 2018 National Platform Meeting on Disaster Risk Reduction, followed by a breakout session on youth engagement. This recognition at the national level is needed to open space for youth voices and foster innovation.

\section{Communication innovations, opportunities, and challenges}

Risk communication in this age of social media, fake news, and widespread misinformation must engage our heterogeneous population. Millennials and youth, as discussed above, are more likely to use online digital sources including social media, blogs, online news platforms, comedy/news commentary shows but also use traditional media sources including television, radio, and print newspapers (Environics 2017). CPIP (PHAC 2015) incorporates a risk communication approach which includes social marketing and social media. The emergence of social media platforms both challenge preparedness and response while representing immediate communication channels for transmission of updates and messages (Rossmann et al. 2018). Social media platforms can also amplify risk messages; however, the communication dynamics is multidirectional. Risk communication using Twitter, for 
example, will include postings and responses from experts, stakeholders, journalists, general public, and possibly automated bots (Mønsted et al. 2017). Journalists will use Twitter to gather new information and to disseminate news stories (Fellenor et al. 2017). Social media represents not only an opportunity to transmit information and update the public, but also to track inquiries, rumours, and myths by monitoring various social media platforms (Panagiotopoulos et al. 2016; Fellenor et al. 2017). Twitter now occupies an established space for crisis communication and discussion, given the immediacy of message communications and updates regarding situational emergencies (Fellenor et al. 2017). The digital divide, however, also suggests that social media can contribute to further marginalization of high-risk populations. Age, socio-economic status, rural and remote geography, and disability may all contribute to decreased use of social media, such that public health organizations will still require multimedia risk communication strategies including outreach, traditional media, and social media platforms.

In the age of social media, information gaps will be readily filled with rumour, conjecture, and myth. False information is perceived as novel and fresh and is spread via Twitter up to six times faster than true information (Vosoughi et al. 2018). Humans are more likely to spread misinformation than Twitter bots (Vosoughi et al. 2018), suggesting that classic principles of risk communication including transparency, acknowledgement of scientific uncertainties, translating scientific information for the lay public, and commitments by governments and agencies to be accountable and regulate risks appropriately is still applicable using a social media context (Leiss 2004). Automated Twitter bots can be programmed within a social network to behave in a human-like manner, disperse messages within typical diurnal periods and within a geographic locus (Mønsted et al. 2017). Twitter bots amplify and spread both false and true information at similar rates (Vosoughi et al. 2018) and thus could be used opportunistically during a pandemic to spread evidencebased facts, vetted risk communication messages in response to the rumours and misinformation within geographic-Twitter networks.

Risk communication of $2009 \mathrm{pH} 1 \mathrm{~N} 1$ and the associated vaccine campaign was generally perceived as confusing by the Canadian public, due to mixed messages, perceptions of the pandemic risk, and the resulting immunization campaign (Driedger et al. 2018). Effective risk communication strategies must acknowledge scientific uncertainties and appreciate that public perceptions of risks are often quite different from scientists and government regulators (Leiss 2004). Perceptions of risk, as discussed, are depended on locus of control such that individuals at high risk, who are vulnerable and powerless due to the social gradient of risk (O'Sullivan and Bourgoin 2010), may reframe, mistrust, lose confidence in the risk information provided (Driedger et al. 2018). Perceptions of powerlessness in the face of a pending emergency may provoke xenophobia (blaming other groups), blaming institutions, or disengagement (Driedger et al. 2018). Public responses during a pandemic require modification or adoption of specific behaviours including handwashing hygiene, vaccination, and social distancing. The element of trust between the public and health agencies is a significant factor in public behaviour change such as vaccination (Driedger et al. 2018).

\section{Closing remarks}

Pandemic planning and acknowledgement of populations at disproportionate risk have progressed tremendously since the world was startled by SARS 15 years ago. Awareness and open acknowledgement of the social gradient of risk by all actors involved in 
pandemic planning and response is an important systemic change. Going forward, to maintain momentum towards inclusive engagement in the implementation of a wholeof-society approach to pandemic planning, there needs to be complementary application of an asset-oriented lens with institutional space for social participation in planning and governance. Change in this type is complex and involves shifting perceptions about people and functional limitations. Use of person-first language and creation of opportunities to network and develop asset literacy are two practical solutions to open the door for active engagement in the coming years. Diversity in Canada is our strength, and innovative solutions will emerge through social participation of diverse groups of citizens who are welcomed and supported by leaders with an upstream vision.

Acknowledgements This study was funded in part by a grant awarded to T. O'Sullivan by the Social Sciences and Humanities Research Council (SSHRC). The authors would like to thank Vanessa Bournival for her support in compiling the provincial pandemic plans.

Funding Funding was provided by Social Sciences and Humanities Research Council of Canada (Grant No. 435-2016-1260).

\section{References}

Amaratunga C, Phillips KP, O’Connor E, O’Sullivan TL, Boscoe M, Lemyre L, Krewski D (2010) The need for healthcare worker sex and gender-sensitive supports during infectious disease outbreaks. In: Tyshenko M, Paterson C (eds) SARS unmasked: risk communication of pandemics and influenza in Canada. McGill-Queen's University Press, Montreal, pp 172-187

Bocking N, Matsumoto CL, Loewen K, Teatero S, Marchand-Austin A, Gordon J, Fittipaldi N, McGeer A (2016) High incidence of invasive group A streptococcal infections in remote indigenous communities in northwestern Ontario, Canada. Open Forum Infect Dis 4(1):ofw243. https://doi. org/10.1093/ofid/ofw243

Bradford LEA, Bharadwaj LA, Okpalauwaekwe U, Waldner CL (2016) Drinking water quality in Indigenous communities in Canada and health outcomes: a scoping review. Int J Circumpolar Health 75(1):32336. https://doi.org/10.3402/ijch.v75.32336

Canadian Intergovernmental Conference Secretariat (2018) Meeting of federal-provincial-territorial ministers responsible for emergency management 831-202. http://www.scics.ca/en/conference/ meeting-of-federal-provincial-territorial-ministers-responsible-for-emergency-management-3/. Accessed 29 May 2018

Canadian Mental Health Association-Ontario (2018) Lesbian, gay, bisexual, trans and queer identified people and mental health. http://ontario.cmha.ca/documents/lesbian-gay-bisexual-trans-queer-ident ified-people-and-mental-health/. Accessed 1 June 2018

Choudhury M, Haque CE (2018) Interpretations of resilience and change and the catalytic roles of media: a case of Canadian daily newspaper discourse on natural disasters. Environ Manag 61:236-248. https:// doi.org/10.1007/s00267-017-0980-7

Cox R, Scanell L, Heykoop C, Tobin-Gurley J, Peek L (2017) Understanding youth disaster recovery: the vital role of people, places, and activities. IJDRR 22:249-256. https://doi.org/10.1016/j.ijdrr .2017.03.011

CROP (2017) The values, needs and realities of LGBT people in Canada in 2017. Research report prepared for: Fondation Jasmin Roy. http://fondationjasminroy.com/en/initiative/lgbt-realities-survey/. Accessed 1 June 2018

Driedger SM, Maier R, Jardine C (2018) 'Damned if you do, and damned if you don't': communicating about uncertainty and evolving science during the H1N1 influenza pandemic. J Risk Res. https://doi. org/10.1080/13669877.2018.1459793

Enarson E, Morrow BH (eds) (1998) The gendered terrain of disaster: through women's eyes. Greenwood, Westport 
Enarson E, Walsh S (2007) Integrating emergency management and high-risk populations: survey report and action recommendations, Canadian Red Cross. http://www.redcross.ca/cmslib/general/dm_high_ risk_populations.pdf. Accessed 30 May 2018

Environics Institute for Survey Research (2017) Canadian millennials social values study. https://www.envir onicsinstitute.org/projects/project-details/canadian-millennial-social-values-study. Accessed 30 May 2018

Fellenor J, Barnett J, Potter C, Urquhart J, Mumford JD, Quine CP (2017) The social amplification of risk on Twitter: the case of ash dieback disease in the United Kingdom. J Risk Res. https://oi. org/10.1080/13669877.2017.1281339

Galtung J (1969) Violence, peace and peace research. J Peace Res 6:168-191

Gostin LO, Meier BM, Huffstetler H (2018) Human rights in global health governance. Glob Health Gov 12:4-10

International Centre for Infectious Diseases (2010) Issues in pandemic influenza responses for marginalized urban populations: key findings and recommendations from consultation meetings and key informant interviews. ICID. http://www.homelesshub.ca/sites/default/files/Issues\%20in\%20Pandemic\%20Pre paredness\%20-\%20Final\%20report.pdf. Accessed 30 May 2018

Jung JJ, Pinto R, Zarychanski R, Cook DJ, Jouvet P, Marshall JC, Kumar A, Long J, Rodin R, Fowler RA, Canadian Critical Care Trials Group H1N1 Collaborative (2017) 2009-2010 Influenza A(H1N1)related critical illness among Aboriginal and non-Aboriginal Canadians. PLoS ONE 12(10):e0184013

Kailes J, Enders A (2007) Moving beyond special needs: a function-based framework for emergency management and planning. J Disabil Policy Stud 17(4):230-237

Kickbusch I, Sakellarides C (2006) Flu City-Smart City: applying health promotion principles to a pandemic threat. Health Promot Int 21(2):85-87

Kirschenbaum A (2006) Families and disaster behavior: a reassessment of family preparedness. Int J Mass Emerg Dis 24(1):111-143

LaPierre TA, Zimmerman MK (2012) Career advancement and gender equity in healthcare management. Gend Manag Int J 27(2):100-118

Leiss W (2004) Effective risk communication practice. Tox Lett 149:399-404

Lemyre L, Gibson S, Zlepnig J, Meyer-Macleod R, Boutette P (2009) Emergency preparedness for higher risk populations: psychosocial considerations. Rad Protect Dos 134(3-4):207-214

Martin K, Medical Needs Task Force of the Emergency Preparedness for People with Disabilities Committee (2009) A shared responsibility: the need for an inclusive approach to emergency planning for people with disabilities, BC Coalition of People With Disabilities. http://disabilityalliancebc.org/exsum m_asharedresponsibility/. Accessed 30 May 2018

McKnight JL, Kretzmann JP (2011) Chapter 9. In: Minkler M (ed) Community organizing and community building for health, 2nd edn. Rutgers University Press, New Brunswick, pp 158-172

Mønsted B, Sapieżyński P, Ferrara E, Lehmann S (2017) Evidence of complex contagion of information in social media: an experiment using Twitter bots. PLoS ONE 12(9):e0184148

National Advisory Committee on SARS and Public Health (2003) Learning from SARS: renewal of public health in Canada. Health Canada. http://www.phac-aspc.gc.ca/publicat/sars-sras/pdf/sars-e.pdf. Accessed 30 May 2018

O’Connor E, O'Sullivan T, Amaratunga C, Thille P, Phillips KP, Carter M, Lemyre L (2009) Risk Communication with nurses during infectious disease outbreaks: learning from SARS. J Emerg Manag $7(5): 48-56$

O’Sullivan TL (2009) Support for families coping with stroke or dementia: special consideration for emergency management. Rad Protect Dos 134(3-4):197-201

O'Sullivan TL, Amaratunga CA (2009) Supporting women and men on the front lines of biological disaster. In: Enarson D, Chakraarti PGD (eds) Women, gender and disaster: global issues and initiatives. Sage Publications, Delhi, pp 165-170

O’Sullivan T, Bourgoin M (2010) Vulnerability in influenza pandemic: looking beyond medical risk. Public Health Agency of Canada. https://homelesshub.ca/sites/default/files/attachments/Lit\%20Review\%20 -\%20Vulnerability\%20in\%20Pandemic_FINAL.pdf. Accessed 19 Feb 2019

O'Sullivan TL, Amaratunga C, Hardt J, Gibson D, Phillips K, Corneil W (2007) Are we ready? Evidence of support mechanisms for Canadian health care workers in multi-jurisdictional emergency planning. CJPH 98(5):358-363

O’Sullivan TL, Dow D, Turner MC, Lemyre L, Corneil W, Krewski D, Phillips KP, Amaratunga CA (2008) Disaster and emergency management: Canadian nurses' perceptions of preparedness on hospital front lines. Prehosp Disaster Med 23(3):s11-s18 
O’Sullivan TL, Amaratunga CA, Phillips KP, Corneil W, O’Connor E, Lemyre L, Dow D (2009) If schools are closed, who will watch our kids? Family caregiving and other sources of role conflict among nurses during large scale outbreaks. Prehosp Disaster Med 24(4):321-325

O'Sullivan T, Ghazzawi A, Stanek A, Lemyre L (2012) We don't have a back-up plan: an exploration of family contingency planning following stroke. Soc Work Health Care 51(6):531-551

O’Sullivan TL, Toal-Sullivan D, Charles K, Corneil W, Bourgoin M (2013) Community resilience through a functional capabilities lens: the CHAMPSS framework. The EnRiCH International Collaboration. http://enrichproject.ca/publications-and-resources.html. Accessed 29 May 2018

O’Sullivan T, Fahim T, Gagnon E (2017) Asset literacy following stroke: implications for disaster resilience. Disaster Med Public Health Prep. https://doi.org/10.1017/dmp.2017.66

O’Sullivan TL, Kuziemsky CE, Corneil W, Lemyre L, Franco Z (2014) The EnRiCH community resilience framework for high-risk populations. PLOS Curr Disasters. https://doi.org/10.1371/currents.dis.11381 $147 \mathrm{bd} 5 \mathrm{e} 89 \mathrm{e} 38 \mathrm{e} 78434 \mathrm{a} 732 \mathrm{f} 17 \mathrm{db}$

Panagiotopoulos P, Barnett J, Bigdeli AZ, Sams S (2016) Social media in emergency management: twitter as a tool for communicating risks to the public. Technol Forecast Soc Change 111:86-96

Patel S, Paulsen C, Heffernan C, Saunders D, Sharma M, King M, Hoeppner V, Orr P, Kunimoto D, Menzies D, Christianson S, Wolfe J, Boffa J, McMullin K, Lopez-Hille C, Senthilselvan A, Long $\mathrm{R}$ (2017) Tuberculosis transmission in the Indigenous peoples of the Canadian prairies. PLoS ONE 12(11):e0188189

Pearce L (2003) Disaster management and community planning, and public participation: how to achieve sustainable hazard mitigation. Nat Hazards 28:211-228

Phillips KP, O’Sullivan TL, Dow D, Amaratunga C (2011) Infectious respiratory disease outbreaks and pregnancy: occupational health and safety concerns of Canadian nurses. Prehosp Disaster Med 26(2):114-121

Pickering C, O’Sullivan TL, Généreux M, David MD, Roy M, Petit G, Lane D, Bournival V (2017) Capability and vulnerability: a discourse analysis of multi-jurisdictional emergency planning documents. Prehosp Disaster Med 32(Suppl. 1):s182-s183. https://doi.org/10.1017/S1049023X17005179

Public Health Agency of Canada (2009) Canadian pandemic influenza preparedness for the health sector: pandemic influenza psychosocial annex. Public Health Agency of Canada. https:/www.canada.ca/ content/dam/phac-aspc/migration/phac-aspc/cpip-pclcpi/assets/pdf/annex_p-eng.pdf. Accessed 1 June 2018

Public Health Agency of Canada (2015) Canadian pandemic influenza preparedness: planning guidance for the health sector. http://www.phac-aspc.gc.ca/cpip-pclcpi/assets/pdf/report-rapport-2015-eng. pdf. Accessed 19 Feb 2019

Public Health Agency of Canada (2015) Canadian pandemic influenza preparedness: planning guidance for the health sector. Public Health Agency of Canada. https://www.canada.ca/en/public-health/servi ces/flu-influenza/canadian-pandemic-influenza-preparedness-planning-guidance-health-sector.html. Accessed 30 May 2018

Rossmann C, Meyer L, Schulz PJ (2018) The mediated amplification of a crisis: communicating the A/H1N1 pandemic in press releases and press coverage in Europe. Risk Anal. https://doi.org/10.1111/risa.12841

Smylie J, Firestone M (2016) The health of indigenous peoples. In: Raphael D (ed) Social determinants of health: Canadian perspectives. Canadian Scholars' Press, Toronto

Standing Senate Committee on Social Affairs, Science and Technology (2010) Canada's response to the $2009 \mathrm{H} 1 \mathrm{~N} 1$ influenza pandemic. Canada Senate, Ottawa. https://www.google.com/ url?sa=t\&rct=j\&q=\&esrc=s\&source=web\&cd=1\&ved=0ahUKEwiKn_L747LbAhVH1IMKHfssAS AQFggnMAA\&url=https $\% 3 \mathrm{~A} \% 2 \mathrm{~F} \% 2 \mathrm{Fsencanada} . \mathrm{ca} \% 2 \mathrm{Fcontent} \% 2 \mathrm{Fsen} \% 2 \mathrm{Fcommittee} \% 2 \mathrm{~F} 403$ $\% 2$ Fsoci\%2Frep\%2Frep15dec10-e.pdf\&usg=AOvVaw0xAEtubqlMdUX-uDknTXtV. Accessed 1 June 2018

Statistics Canada (2017a) Families, households and marital status: Key results from the 2016 Census. https ://www.statcan.gc.ca/daily-quotidien/170802/dq170802a-eng.htm. Accessed 1 June 2018

Statistics Canada (2017b) Same-sex couples in Canada in 2016 http://www12.statcan.gc.ca/census-recen sement/2016/as-sa/98-200-x/2016007/98-200-x2016007-eng.cfm. Accessed 1 June 2018

Statistics Canada (2017c) Portrait of children's family life in Canada in 2016. http://www12.statcan.gc.ca/ census-recensement/2016/as-sa/98-200-x/2016006/98-200-x2016006-eng.cfm. Accessed 1 June 2018

Statistics Canada (2018) First nations people, métis and inuit in Canada: diverse and growing populations. http://www.statcan.gc.ca/pub/89-659-x/89-659-x2018001-eng.htm. Accessed 1 June 2018

Tanaka T, Nakajima K, Murashima A, Garcia-Bournissen F, Koren G, Ito S (2009) Safety of neuraminidase inhibitors against novel influenza A (H1N1) in pregnant and breastfeeding women. CMAJ 181(1-2):55-58 
Trudeau J (2017) Government of Canada initiatives to support LGBTQ2 communities and promote diversity and inclusion. https://pm.gc.ca/eng/news/2017/11/28/government-canada-initiatives-support-lgbtq 2-communities-and-promote-diversity-and. Accessed 4 June 2018

Truth and Reconciliation Commission of Canada (2015) Calls to action www.trc.ca. Accessed 1 June 2018

United Nations Office for Disaster Risk Reduction (2015) Sendai framework for disaster risk reduction. http://www.unisdr.org/files/43291_sendaiframeworkfordrren.pdf. Accessed 4 June 2018

Vosoughi S, Roy D, Aral S (2018) The spread of true and false news online. Science 359(6380):1146-1151

Webster PC (2016) Canada's Indigenous suicide crisis. Lancet 387(10037):2494

World Health Organization (2009) Whole-of-society pandemic readiness. WHO. http://www.who.int/influ enza/preparedness/pandemic/2009-0808_wos_pandemic_readiness_final.pdf. Accessed 4 June 2018

Publisher's Note Springer Nature remains neutral with regard to jurisdictional claims in published maps and institutional affiliations. 